\title{
Treatment of the acute severe pulmonary embolism using endovascular methods
}

\author{
Inger E. Keussen ${ }^{1 \mathrm{~A}, \mathrm{~B}, \mathrm{D}, \mathrm{E}}$, Carina Bursj00 ${ }^{1 \mathrm{~B}, \mathrm{D}, \mathrm{E}, \mathrm{F}}$, Wojciech Cwikiel ${ }^{2 \mathrm{~A}, \mathrm{~B}, \mathrm{E}}$ \\ 'Department of Radiology, Lund University, Lund, Sweden \\ 2Faculty of Medicine, Department of Clinical Sciences, Lund University, Lund, Sweden
}

\section{Abstract}

Purpose: To present a single-centre experience with endovascular treatment of patients with severe symptoms secondary to acute pulmonary embolism (PE).

Material and methods: Twenty-five patients were treated due to contraindications or deficient effects of systemic thrombolytic therapy. The patients were treated with a combination of fragmentation and aspiration, only aspiration, or only fragmentation, and with catheter-directed thrombolytic therapy.

Results: The saturation was improved following treatment in all patients, except in one where the procedure could not be completed. There were no immediate or late procedure-related complications.

Conclusions: Endovascular treatment of severe PE is a safe and efficient option in patients with failing effect or contraindication to systemic thrombolysis.

Key words: endovascular procedure, pulmonary embolism, embolectomy.

\section{Introduction}

Acute pulmonary embolism (PE) is a severe condition with a high risk of mortality. The severity of symptoms may vary, but most often include dyspnoea, chest pain, cough, and in some cases haemoptysis. Unstable patients are presented with a drop in blood pressure (BP) and tachycardia, and untreated they may progress to circulatory collapse [1]. Following clinical examination and laboratory tests the diagnosis is commonly verified by echocardiography (ECO) and/or computer tomography (CT). A pulmonary angiography (PAI) and pulmonary ventilation/perfusion scan may be performed in specialised hospitals [2-4].

Haemodynamically unstable patients are traditionally treated with systemic thrombolysis or open embolectomy [5]. However, there are several contraindications for thrombolysis, for instance current or threatening bleed- ing, stroke, recent surgery or delivery, trauma, or malignant diseases.

For patients with contraindications or insufficient effect of systemic thrombolysis, endovascular treatment may be an option [5-11]. Endovascular methods include catheter-directed administration of thrombolytics (CDT), fragmentation and/or aspiration of emboli, or a combination of these methods. An inferior vena cava (IVC) filter is often placed to prevent further embolisation [12-19].

We retrospectively present our results of the endovascular treatment in 25 patients with acute, severe PE.

\section{Material and methods}

Of the 25 patients, 17 were male and eight female, age range 31-83 years. The treatment was performed due to contraindications including gastro-intestinal (G-I) bleeding $(n=2)$, malignancy $(n=4)$, stroke $(n=3)$, recent

\section{Correspondence address:}

Inger E. Keussen, Department of Radiology, Lund University, Getingevägen, 22185 Lund, Sweden, phone: +46705810710, e-mail: inger.keussen@med.lu.se

Authors' contribution:

A Study design - B Data collection · C Statistical analysis · D Data interpretation - E Manuscript preparation · F Literature search · G Funds collection 
Table 1. Patients and treatments

\begin{tabular}{|c|c|c|c|c|c|c|}
\hline $\begin{array}{l}\text { Patient } \\
\text { no. }\end{array}$ & Age & Gender & History/Actual problem & Indication for endovascular treatment & IVC filter & $\begin{array}{c}\text { Endovascular } \\
\text { treatment }\end{array}$ \\
\hline 1 & 58 & M & Pulmonary transplant & Recent surgery & Yes & CDT \\
\hline 2 & 64 & M & Liver malignancy & Recent surgery & Yes & A \\
\hline 3 & 69 & M & Chest pain + cardiac arrest & Insufficient effect of systemic thrombolysis & No & $\mathrm{F}+\mathrm{A}$ \\
\hline 4 & 70 & M & Intracranial haemorrhage & Stroke & Yes & $\mathrm{F}+\mathrm{A}$ \\
\hline 5 & 70 & $\mathrm{~F}$ & Chest pain & Risk of bleeding (aorta aneurysm) & Yes & $\mathrm{F}+\mathrm{A}$ \\
\hline 6 & 79 & M & Pneumonia + sepsis & Insufficient effect of systemic thrombolysis & No & $\mathrm{F}$ \\
\hline 7 & 42 & M & Urachus malignancy & Malignancy & Yes & A \\
\hline 8 & 58 & $\mathrm{~F}$ & Leiomyosarcoma & Malignancy & No & $\mathrm{F}+\mathrm{A}+\mathrm{CDT}$ \\
\hline 9 & 72 & M & Dyspnoea & Migrating thrombus & No & $\mathrm{F}+\mathrm{A}$ \\
\hline 10 & 68 & $\mathrm{~F}$ & Dyspnoea & GI-bleeding & Yes & $\mathrm{F}$ \\
\hline 11 & 68 & $\mathrm{~F}$ & Cardiac arrest & Recent CPR & Yes & $\mathrm{F}+\mathrm{A}$ \\
\hline 12 & 66 & M & Cerebral malignancy & Gl-bleeding & Yes & $\mathrm{F}+\mathrm{A}$ \\
\hline 13 & 78 & M & Dyspnoea & Insufficient effect of systemic thrombolysis & No & $\mathrm{F}+\mathrm{A}$ \\
\hline 14 & 63 & $\mathrm{~F}$ & Stroke + cardiac arrest & Stroke & Yes & $\mathrm{F}+\mathrm{A}$ \\
\hline 15 & 82 & M & Dyspnoea & Insufficient effect of systemic thrombolysis & No & $\mathrm{F}+\mathrm{CDT}$ \\
\hline 16 & 71 & M & Dyspnoea & Insufficient effect of systemic thrombolysis & Yes & $\mathrm{F}+\mathrm{A}$ \\
\hline 17 & 61 & M & Pancreatic malignancy & Malignancy & No & $\mathrm{F}$ \\
\hline 18 & 64 & M & Intracranial haemorrhage & Stroke & Yes & A \\
\hline 19 & 69 & M & Pneumonia + deep vein thrombosis & Risk of bleeding (infection) & Yes & $\mathrm{F}+\mathrm{A}$ \\
\hline 20 & 57 & M & Chest pain + dyspnoea & Risk of bleeding (after coronary a i) & Yes & $\mathrm{F}$ \\
\hline 21 & 69 & $\mathrm{~F}$ & Dyspnoea & Malignancy & Yes & $\mathrm{F}+\mathrm{A}$ \\
\hline 22 & 43 & $\mathrm{~F}$ & Dyspnoea & Insufficient effect of systemic thrombolysis & Yes & A \\
\hline 23 & 74 & M & Intracranial surgery & Recent surgery & Yes & $\mathrm{F}+\mathrm{A}$ \\
\hline 24 & 31 & $\mathrm{~F}$ & Recent delivery & Insufficient effect of systemic thrombolysis & No & $\mathrm{F}+\mathrm{A}$ \\
\hline 25 & 63 & M & Dyspnoea + cardiac arrest & Insufficient effect of systemic thrombolysis & Yes & $\mathrm{F}+\mathrm{A}$ \\
\hline
\end{tabular}

A - aspiration, CDT - catheter-directed therapy, CPR - cardio pulmonary resuscitation, $\mathrm{F}$ - fragmentation

surgery $(n=3)$, risk of bleeding $(n=3)$, recent cardio-pulmonary resuscitation $(n=1)$, migrating thrombus, and insufficient effect of systemic thrombolysis $(n=8)$ (Table 1$)$.

Ten patients presented at the emergency department with dyspnoea and five with chest pain/cardiac arrest. The remaining patients were hospitalised at the time of acute $\mathrm{PE}$ due to malignancy, stroke, or palliation. Five patients were haemodynamically unstable with $\mathrm{SBP}<90$ at the time of the procedure. The saturation was moderate or severely decreased in all patients, measuring between 69 and 97\% (mean 86\%) with oxygen support. The respiratory frequency was measured in 19 patients, with a mean value of $23 / \mathrm{min}$.

Echocardiography (ECO) was performed in 20 patients, and 19 or them had signs of right heart strain. The extent of the PE was verified by CT scans in all patients. The Miller Index was used to quantify pulmonary arterial obstruction, with a mean value of 14.6 (patient number $=11,12,13,14,15,20)$.
All procedures except one were performed with local anaesthesia, with continuous monitoring of BP, heart rate, and saturation. Following puncture of the right common femoral vein, an IVC filter (Celect, Cook Sweden AB, Askim, Sweden) was positioned in the infrarenal IVC if indicated, to prevent further embolisation. Thereafter, a $70 \mathrm{~cm}$ long $9 \mathrm{~F}$ introducer was placed with the tip in the IVC close to the right atrium. The tip of a $7 \mathrm{~F}$ APC catheter (Cook Sweden AB) was thereafter advanced through the introducer to the left and right main pulmonary arteries and diagnostic angiograms were performed. Subsequently the introducer tip was advanced over a Glidewire (Terumo Sweden AB, Västra Frölunda, Sweden) to the main pulmonary trunk. In cases with occlusive central emboli fragmentation attempt was done using rotation of the tip of a $5 \mathrm{~F}$ pigtail catheter (Cordis, Sollentuna, Sweden) placed over the guidewire in the left and/or right pulmonary artery. Following exchange of the guidewire to a 0.018 wire 

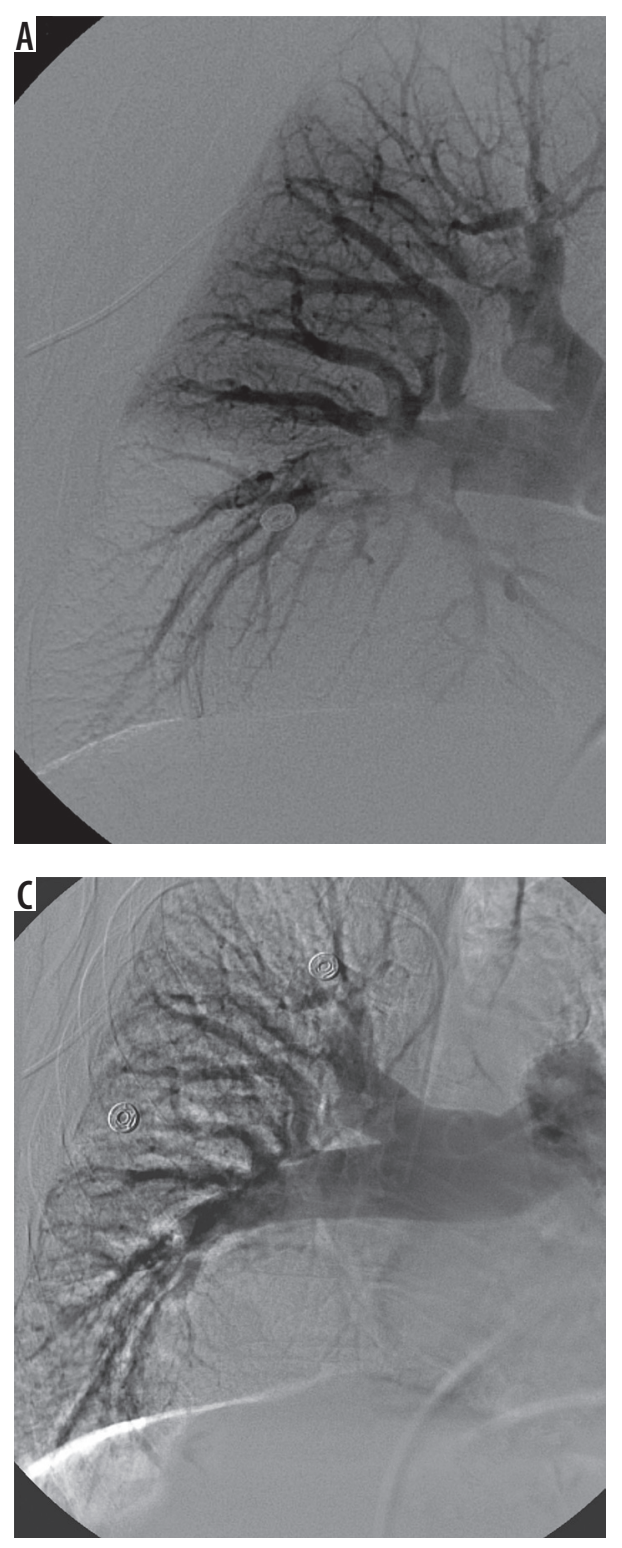

(Boston Scientific, Helsingborg, Sweden), an ArrowTrerotola positioned over the wire percutaneous thrombolytic device (PTD - Arrow Int. Inc., Reading PA, USA) [20] was advanced into the pulmonary trunk, and fragmentation of the emboli in the main and segmental branches was performed. Aspiration of emboli was done using an $8 \mathrm{~F}$ JR4 guiding catheter (Cordis). In three patients CDT was administrated though a 4 F Cobra C2 catheter (Cordis) or a 4 F MPA catheter (Terumo) placed with the tip in the embolus in the main right or left pulmonary artery, using alteplase (Actilyse, Boerhinger Ingelheim AB, Stockholm, Sweden). The results of all the treatments were verified during the procedure by multiple contrast injections and by final angiography (Figure 1A-C).

\section{Results}

One patient in severe, unstable condition and with extensive PE expired during the attempted fragmentation due to circulatory arrest that could not be reversed.

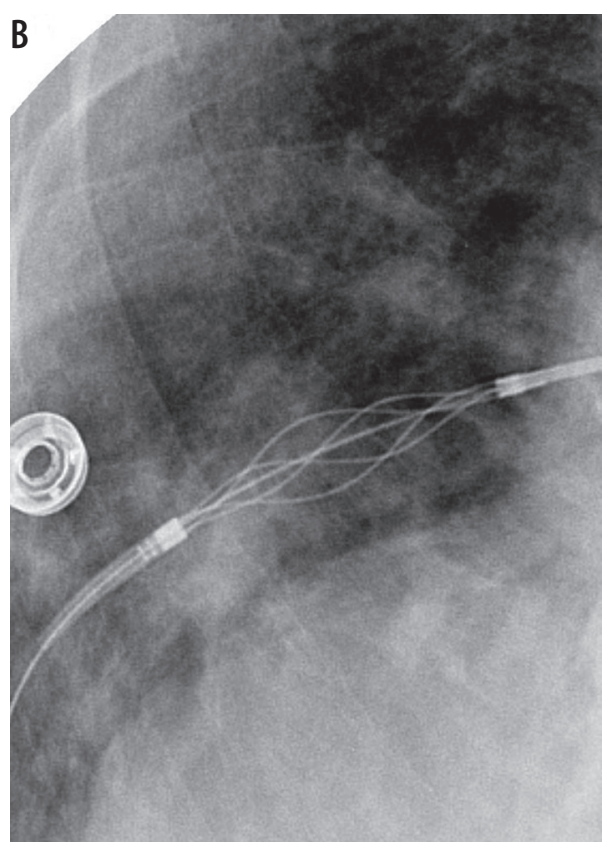

Figure 1. A) Emboli in the right pulmonary artery causing perfusion defects. B) Arrow-Trerotola in place in the artery to the lower lobe. C) Result after the endovascular treatment with improvement of the perfusion

The procedures were successfully completed in the other 24 patients. In 17 patients an IVC filter was placed during the procedure. In 14 of the 23 patients fragmentation and aspiration of the emboli were performed. In four patients aspiration only and in another four fragmentation only was performed. CDT alone was performed in one patient, in whom mechanical or systemic treatment was contraindicated due to recent surgery (patient 1). In two other patients, CDT was combined with mechanical removal (patient 8 and 15) due to large emboli burden.

The final angiography showed improved flow in the pulmonary circulation in all patients. One of these patients was, however, subsequently treated by surgical embolectomy due to recurrent circulatory instability. The treatment had good primary effect with immediate improvement of saturation in all the other patients, and there were no procedure-related complications (Table 1).

The mean time of hospitalisation after the procedure was 12.5 days, including less than half a day of observation in the intensive care unit. 


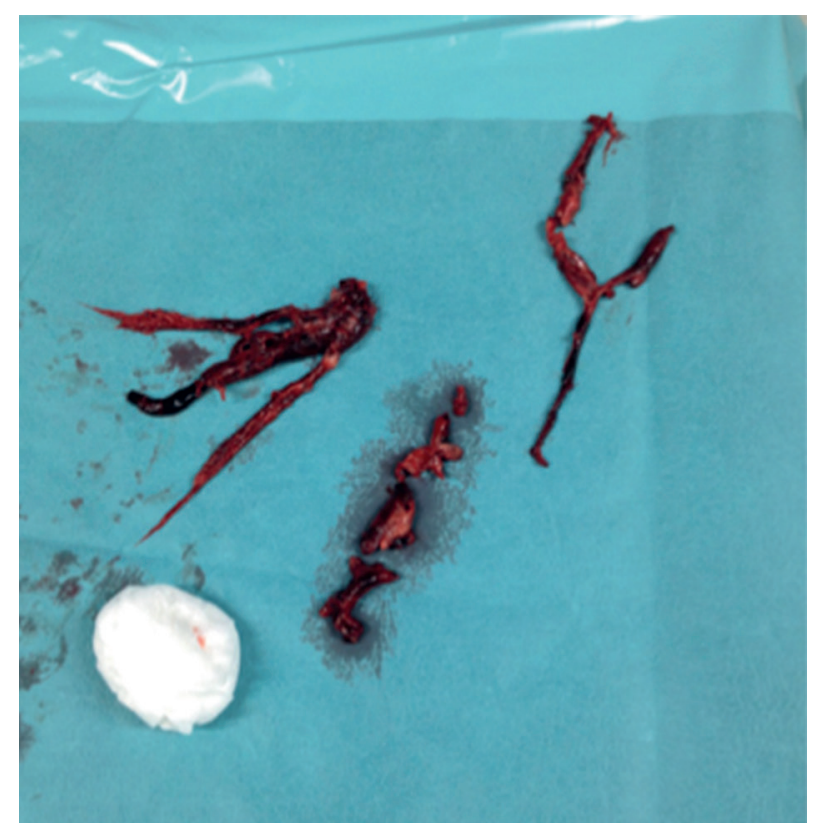

Figure 2. Aspirated emboli

During follow-up (up to 42 months) nine patients expired. One died due to pneumonitis after three days, and one due to anoxia of the brain following heart arrest (reversed prior to the procedure) after 12 days. One patient expired due to aortic dissection more than one year after treatment, two due to unknown causes after more than six months, and the others later due to underlying disorders.

\section{Discussion}

Acute PE is a severe condition with substantial morbidity and mortality (15-18\%) within the first three months [21]. Late complications such as chronic thromboembolic pulmonary hypertension may cause significant morbidity [22]. The traditional treatment includes anticoagulant therapy in haemodynamically stable patients, while unstable patients are treated with systemic thrombolysis or open surgery. Open surgery is an extensive procedure that carries substantial risk of complications [12]. Systemic thrombolysis usually has good effect but contains risks and contraindications, such as ongoing or expected bleeding, recent stroke, trauma, surgery or delivery, known gastrointestinal ulceration, and some malignant diseases.

Endovascular treatment of patients with massive PE was reported previously [6-12]. There are several strate- gies of endovascular treatment. A widely used therapy is CDT, where the thrombolytic agent is administrated directly into the embolus, with a potent local effect $[12,13]$. A percutaneous central PE fragmentation may be done using rotation of, for example, a pigtail catheter. The smaller fragments migrate more peripherally, increasing total pulmonary perfusion and relieving right ventricular afterload, and may augment the effect of the thrombolysis $[12,14]$. Several different aspiration devices are available, some with combined fragmentation with drug infusion-function $[13,15]$. Ultrasound-assisted catheter-directed thrombolysis is another relatively new method, but one that requires treatment lasting about 20 hours [16-19]. We retrospectively report our experience of interventional treatment of patients with severe symptoms secondary to massive PE, in which conventional treatment failed or could not be performed.

All our patients were severely symptomatic, and systemic thrombolysis was contraindicated or unsuccessful in all of them. Due to the urgency of the procedures registration of the different parameters such as pulmonary artery pressure was not performed. The procedures had, however, a primary prompt effect with substantial improvement of saturation, which persisted during the patients' hospital stay.

Mechanical fragmentation of the PE using intravascular methods and devices was previously described [12]. The Arrow-Trerotola PTD is relatively common in the treatment of thrombosed dialysis grafts [20] but may also be used in native fistulas [23] and in peripheral veins [24]. However, to our knowledge use of this device in the treatment of PE was not previously reported. For aspiration of the embolic material we used cardiac guiding catheters due to their large inner lumen and good torque ability, allowing easy positioning in more peripheral branches.

There were no procedure-related complications. Most of our patients had PE secondary to severe underlying diseases, which was the main cause of the prolonged hospital stay after intervention. The causes of deaths were not related to the procedures.

We conclude that the treatment of the acute PE using our methods is safe and efficient in the majority of patients and may be recommended.

\section{Conflict of interest}

The authors report no conflict of interest.

\section{References}

1. Wood KE. Major pulmonary embolism: review of a pathophysiologic approach to the golden hour of hemodynamically significant pulmonary embolism. Chest 2002; 121: 877-905.

2. Perrier A, Roy PM, Sanchez O, et al. Multidetector-row computed tomography in suspected pulmonary embolism. N Engl J Med 2005; 352: 1760-1768.
3. Kucher N, Rossi E, De Rosa M, et al. Prognostic role of echocardiography among patients with acute pulmonary embolism and a systolic arterial pressure of $90 \mathrm{~mm} \mathrm{Hg}$ or higher. Arch Intern Med 2005; 165: 1777-1781.

4. Ten Wolde M, Söhne M, Quak E, et al. Prognostic value of echocardiographically assessed right ventricular dysfunction in pa- 
tients with pulmonary embolism. Arch Intern Med 2004; 164 1685-1689.

5. Büller HR, Agnelli G, Hull RD, et al. Antithrombotic therapy for venous thromboembolic disease: The seventh ACCP conference on antithrombotic and thrombolytic therpy. Chest 2004; 126: 401-428.

6. Dumantepe M, Teymen B, Akturk U, et al. Efficacy of rotational thrombectomy on the mortality of patients with massive and submassive pulmonary embolism. J Card Surg 2015; 30: 324-332.

7. Lee MY, Kim MY, Han JY, et al. Pregnancy-associated pulmonary embolism during the peripartum period: An 8-year experience at a single center. Obstet Gynecol Sci 2014; 57: 260-265.

8. Bayiz H, Dumantepe M, Teymen B, et al. Percutaneous aspiration thrombectomy in treatment of massive pulmonary embolism. Heart Lung Circ 2015; 24: 46-54.

9. Pelliccia F, Schiariti M, Terzano C, et al. Treatment of acute pulmonary embolism: update on newer pharmacologic and interventional strategies. Biomed Res Int 2014; 2014: 410341.

10. Mohan B, Aslam N, Kumar Mehra A, et al. Impact of catheter fragmentation followed by local intrapulmonary thrombolysis in acute high risk pulmonary embolism as primary therapy. Indian Heart J 2014; 66: 294-301.

11. Garcia MJ. Endovascular Management of Acute Pulmonary Embolism Using the Ultrasound-Enhanced EkoSonic System. Semin Intervent Radiol 2015; 32: 384-387.

12. Lin PH, Chen H, Bechara CF, et al. Endovascular interventions for Acute Pulmonary Embolism. Perspect Vasc Surg Endovasc Ther 2010; 22: 171-182.

13. Mostafa A, Briasoulis A, Telila T, et al. Treatment of Massive or Submassive Acute Pulmonary Embolism With Catheter-Directed Throm bolysis. Am J Cardiol 2016; 117: 1014-1020.

14. Fava M, Loyola S, Flores P, et al. Mechanical fragmentation and pharmacologic thrombolysis in massive pulmonary embolism. J Vasc Interv Radiol 1995; 8: 261-266.

15. Özsancak Uğurlu A, Çınar Ö, Caymaz İ, et al. Combined catheter thrombus fragmentation and percutaneous thrombectomy in a pa- tient with massive pulmonary emboli and acute cerebral infarct. Anadolu Kardiyol Derg 2015; 15: 72-74.

16. Kucher N, Boekstegers P, Müller OJ, et al. Randomized, controlled trial of ultrasound-assisted catheter-directed thrombolysis for acute intermediate-risk pulmonary embolism. Circulation 2014; 129: 479-486.

17. Sag S, Nas OF, Kaderli AA. Catheter-directed ultrasound-accelerated thrombolysis may be life-saving in patients with massive pulmonary embolism after failed systemic thrombolysis. J Thromb Thrombolysis 2016; 42: 322-328.

18. Bloomer TL, El-Hayek GE, McDaniel MC. Safety of catheter-directed thrombolysis for massive and submassive pulmonary embolism: results of a multicenter registry and meta-analysis. Catheter Cardiovasc Interv 2017; 89: 754-760.

19. Mohan PP, Manov JJ, Contreras F, et al. Ultrasound-Assisted Catheter-Directed Thrombolysis for Submassive Pulmonary Embolism. Vasc Endovascular Surg 2018; 52: 195-201.

20. Trerotola SO, Vesely TM, Lund GB, et al. Treatment of thrombosed hemodialysis access grafts: Arrow-Trerotola percutaneous thrombolytic device versus pulse-spray thrombolysis. Arrow-Trerotola Percutaneous Thrombolytic Device Clinical Trial. Radiology 1998; 206: 403-414.

21. Goldhaber SZ, Visani L, De Rosa M, et al. Acute Pulmonary Embolism: clinical outcomes in the International Cooperative Pulmonary Embolism Register (ICOPER). Lancet 1999; 353: 1386-1389.

22. Limbrey R, Howard L. Developments in the management and treatment of pulmonary embolism. Eur Respir Rev 2015; 24: 484-497.

23. Shatsky JB, Berns JS, Clark TW, et al. Single-center experience with the Arrow-Trerotola Percutaneous Thrombectomy Device in the management of thrombosed native dialysis fistulas. J Vasc Interv Radiol 2005; 16: 1605-1611.

24. Lee KH, Han H, Lee KJ, et al. Mechanical thrombectomy of acute iliofemoral deep vein thrombosis with use of an Arrow-Trerotola percutaneous thrombectomy device. J Vasc Interv Radiol 2006; 17: 487-495. 